\title{
Case Report \\ 3D Evaluation of Palatal Rugae in Identical Twins
}

\author{
Emiliya Taneva, Carla Evans, and Grace Viana \\ Department of Orthodontics, College of Dentistry, University of Illinois at Chicago, Chicago, IL, USA
}

Correspondence should be addressed to Emiliya Taneva; etanev2@uic.edu

Received 31 December 2016; Revised 19 March 2017; Accepted 9 April 2017; Published 22 May 2017

Academic Editor: Hüsamettin Oktay

Copyright (C) 2017 Emiliya Taneva et al. This is an open access article distributed under the Creative Commons Attribution License, which permits unrestricted use, distribution, and reproduction in any medium, provided the original work is properly cited.

\begin{abstract}
The study of identical twins can point out potential limitations in biometrics and forensic odontology. This case report presents three-dimensional (3D) palatal rugae analysis in monozygotic twins utilizing digital models obtained directly by scanning the maxillary dental arch with the iTero ${ }^{\circledR}$ intraoral digital scanner. The results show that the rugae patterns contain related but not identical features between the pair of identical twins. Dental study models taken on a regular basis for diagnosis and treatment planning in dentistry include the palatal rugae, which could be valuable to forensics in identical twin identification cases.
\end{abstract}

\section{Introduction}

Palatal rugae, also known as plicae palatinae transversae and rugae palatine, are situated in the anterior third of the hard mucosal palate on the roof of the mouth. They appear towards the third month of intrauterine life from connective tissue covering the palatine processes of the maxillary bones. It has been shown in the literature that the palatal rugae are unique and permanent for each person and could be used for human identification [1-11]. Scanning three-dimensional (3D) technology facilitates the computerized matching of palatal rugae patterns in a manner comparable to the current gold standard for assessing fingerprints [12-14]. 3D digital models have been proven as an effective tool in evaluating palatal rugae patterns for human verification and identification [12, 15-18].

There are two basic types of twins: dizygotic (DZ), commonly referred to as fraternal twins, and monozygotic (MZ), referred to as identical twins. A higher concordance rate in MZ twins than in DZ twins has been observed.

Identical twins develop from a single zygote that splits into two individual cells and develops into two individuals. The frequency of monozygotic twins is about $0.4 \%$ across different populations [19]. A dramatic increase in the overall twinning rate has been seen, from 1 in 60 births in 1980 to about 1 in 30 births in 2013. In 2014, there were 135,336 twin births in the United States [20]. Elevated occurrence of the monozygotic twinning rate and increase of the identical twin population have been associated with medically assisted reproduction (MAR) over the past decades [21]. Biometric technologies based on different characteristics such as fingerprints, retina, face, iris, and palm prints have been developed and implemented. Identical twins share the same genetic expression, but not all biometric authentication systems provide successful verification information [22, 23]. Studying additional biometric traits such as the palatal rugae pattern to differentiate between identical twins is an important focus in biometrics and forensic odontology [14].

This case report aims to evaluate the palatal rugae pattern in a pair of identical twins, to assess the related rugae features, and to $3 \mathrm{D}$-compare rugae target points with previously published values using stereolithography technology. Several studies have shown the clinical significance of the individual palatal outlines; however, 3D analysis and matching procedure in identical twins have not been previously investigated.

\section{Materials and Methods}

2.1. Study Design. A 14-year-and-10-month-old female pair of identical twins presented for an initial orthodontic visit. Facial and intraoral photographs, panoramic and lateral cephalometric radiographs, and virtual dental impressions were taken prior to orthodontic treatment (Figures 1 and 2). $3 \mathrm{D}$ digital models of the upper and lower jaws were obtained with the iTero HD 2.9 intraoral digital scanner (Align Technology, Inc., San Jose, CA) (Figure 3) [17, 18]. 

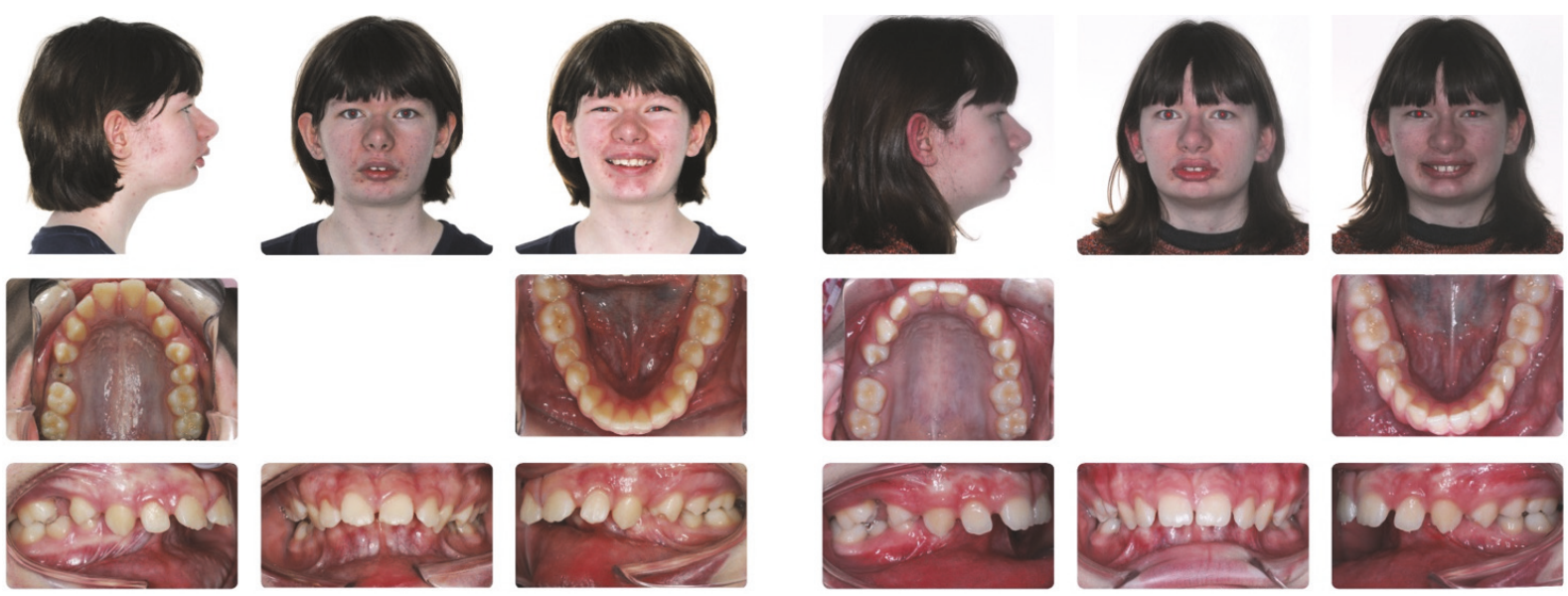

FIGURE 1: Facial and intraoral photographs of the identical twins.
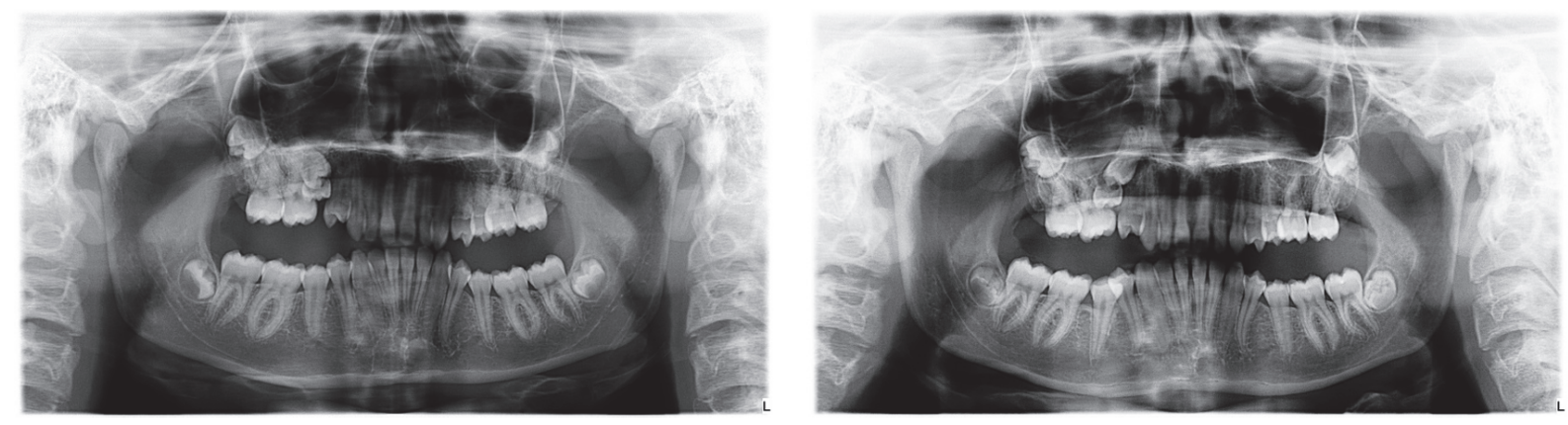

Figure 2: Panoramic radiographs of the identical twins.

2.2. Palatal Rugae Assessment. Stereolithography is a typical modality of rapid prototyping used for producing physical models, patterns, and production parts in a layer-by-layer manner from computer-aided design software (CAD) via $3 \mathrm{D}$ printing. The iTero intraoral digital scanner employs the stereolithography apparatus technology to produce digital models derived from their data $[12,16-18]$. In this case report, the identical twin patients were intraorally scanned with the iTero and digital models were exported into a stereolithography binary format $\left({ }^{*}\right.$.stl) through the MyAlignTech website..stl is an open, industry-standard file format widely used for additive manufacturing and across different 3D modeling interfaces. The assessment, selection, and extraction of the palatal area as well as the $3 \mathrm{D}$ superimposition and matching process of the rugae were conducted using the.stl files imported into the professional widely used engineering processing software Geomagic ${ }^{\circledR}$ Control 14, Geomagic (Research Triangle Park, NC, USA).

The palatal rugae were documented based on their length and shape according to the Lysell, Thomas and Kotze, and Trobo classifications $[8,24,25]$. They were measured in a straight line between the origin and termination and divided into primary (with lengths of $5 \mathrm{~mm}$ or more), secondary (with lengths from 3 to $5 \mathrm{~mm}$ ), and fragmentary (with lengths from 2 to $3 \mathrm{~mm}$ ) rugae. The rugae were also categorized based on their shape as straight, wavy or sinuous, curved, and circular.
2.3. Palatal Superimposition. Processing and analysis of the 3D dental models were done in a set of two. Each digital impression was aligned at the same position and orientation according to the 3D coordinates (e.g., $X, Y$, and $Z$ coordinates). The palatal rugae area of each model was selected and a separate object was extracted consisting only of that area. Manual alignment and global registration functions superimposed and fine-tuned the position of the two scans. 3D Compare analysis was performed which generated a $3 \mathrm{D}$, colorcoded map of the differences between the two palates (Figure 4).

3D surface features were identified using eleven target points: the most medial and lateral end points of the palatal rugae (R1MR, R1LR, R1LL, R2MR, R2ML, R2LR, R2LL, R3MR, R3ML, R3LR, and R3LL). Only 2 medial end points were observed for the palatal rugae on the left side. The deviations for each of the three $X Y Z$ coordinate axes $D x, D y$, and $D z$ and the overall deviation magnitude values for the eleven variables were automatically calculated and recorded in the Geomagic software and then exported into Microsoft ${ }^{\circledR}$ Excel (Figure 5).

The overall deviation magnitude values of the palatal rugae landmarks were compared with values previously published in the literature utilizing the same methodology. The values for the pair of identical twins were compared with the values for the same individuals over time and following 

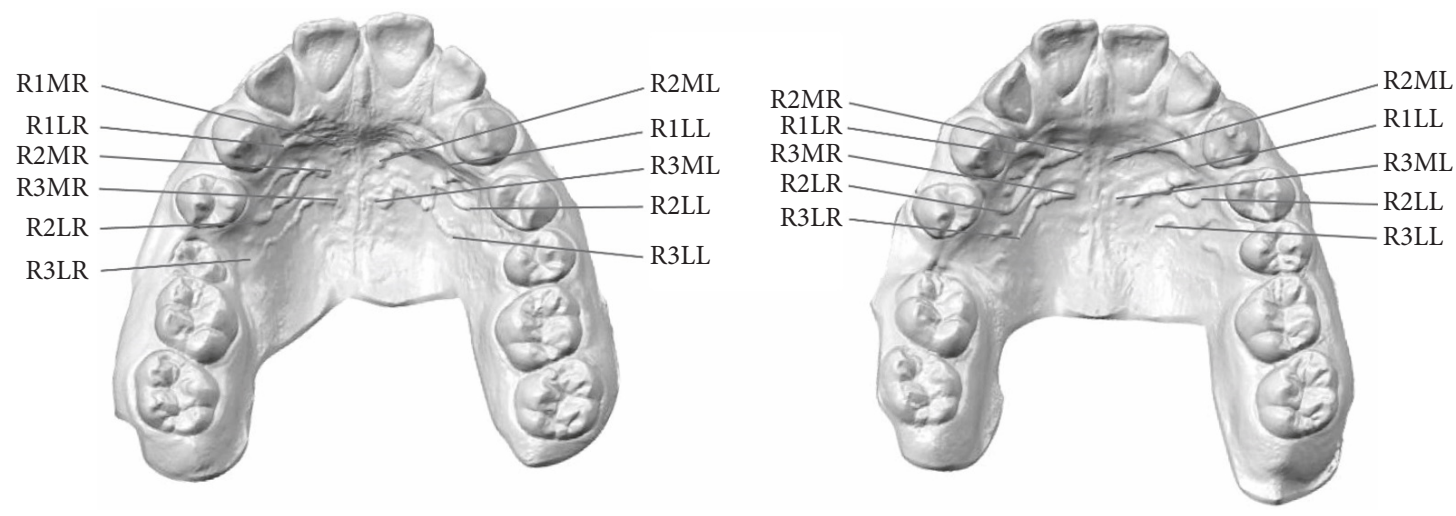

FIGURE 3: Maxillary occlusal digital models of the identical twins with the selected medial and lateral points of the palatal rugae.
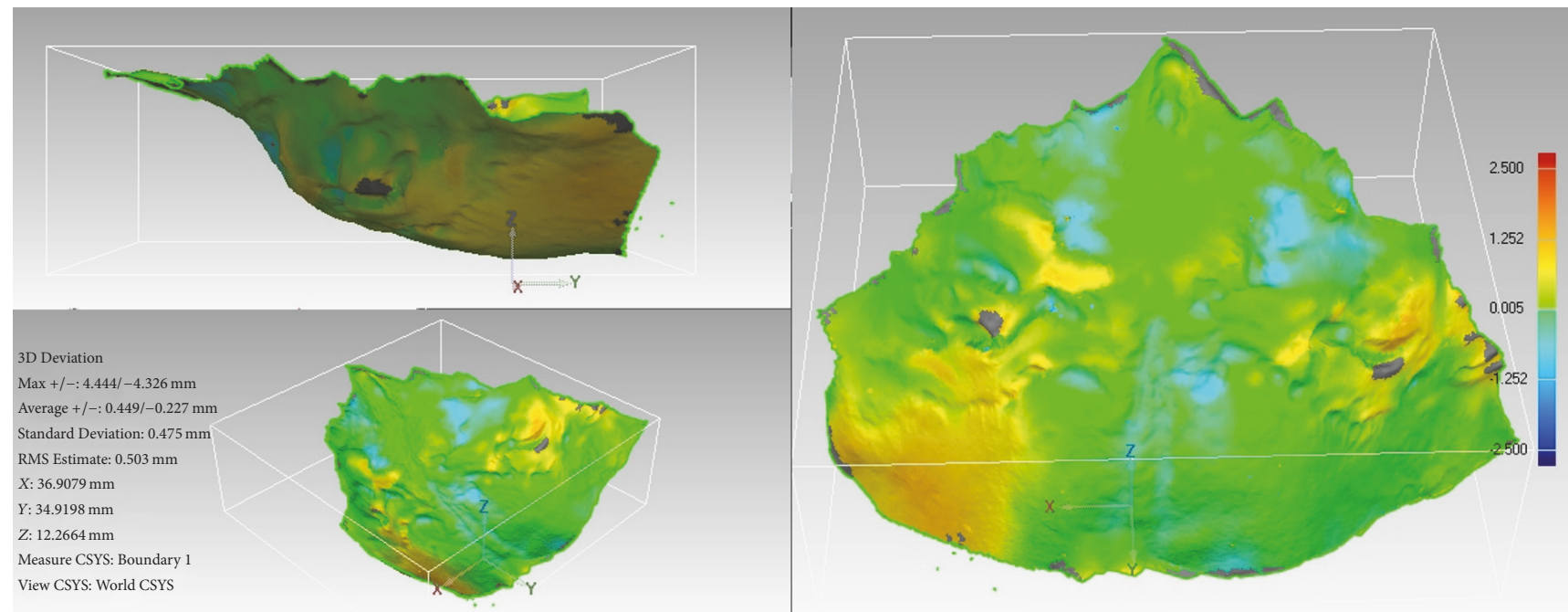

FIGURE 4: Color-coded map generated following 3D Compare analysis.

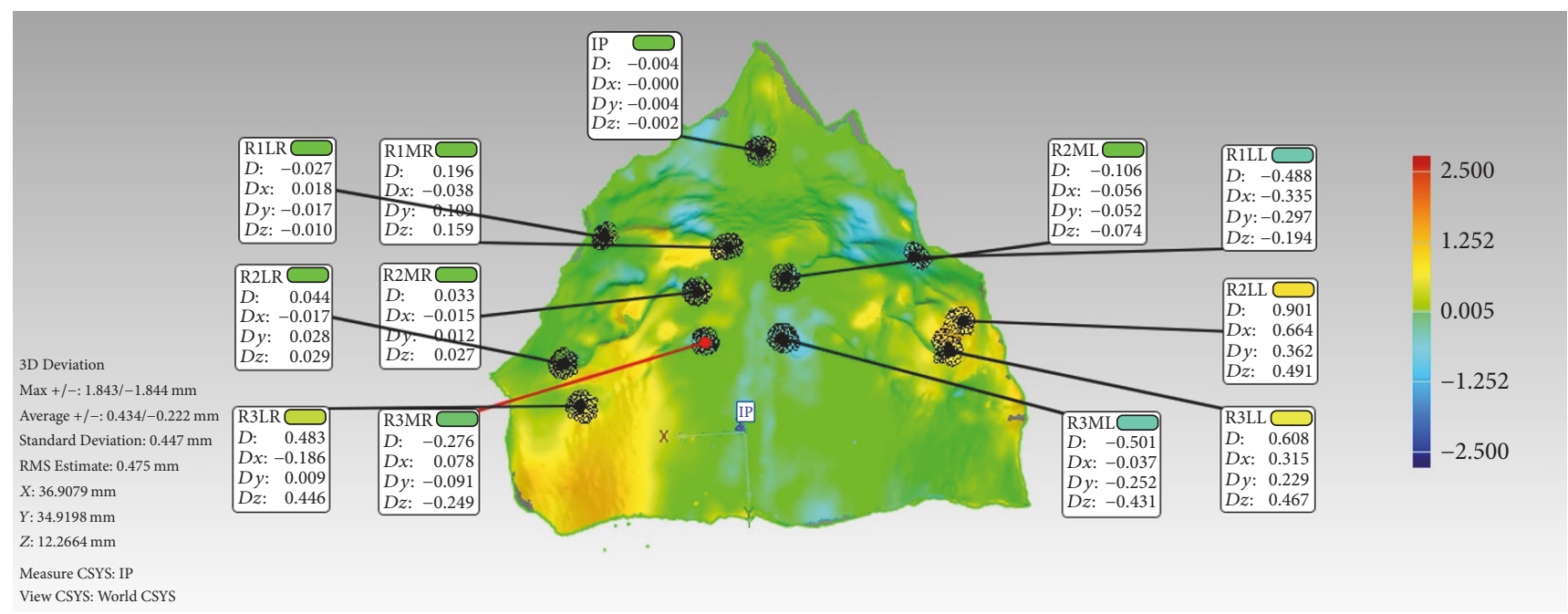

FIGURE 5: Annotation view with selected medial and lateral points of the palatal rugae. 
TABLE 1: Rugae size and shape of the identical twins pair.

\begin{tabular}{|c|c|c|c|c|}
\hline \multirow{2}{*}{ Palatal landmarks } & \multicolumn{2}{|c|}{ Twin 1} & \multicolumn{2}{|c|}{ Twin 2} \\
\hline & Size & Shape & Size & Shape \\
\hline R1R & $10.9 \mathrm{~mm}$ & Straight & Missing & Missing \\
\hline $\mathrm{R} 2 \mathrm{R}$ & $12.6 \mathrm{~mm}$ & Circle & $13.2 \mathrm{~mm}$ & Circle \\
\hline R3R & $13.1 \mathrm{~mm}$ & Sinuous & $11.0 \mathrm{~mm}$ & Sinuous \\
\hline R1L & Missing & Missing & Missing & Missing \\
\hline R2L & $10.6 \mathrm{~mm}$ & Sinuous & $12.2 \mathrm{~mm}$ & Straight \\
\hline R3L & $13.5 \mathrm{~mm}$ & Circle & $13.2 \mathrm{~mm}$ & Circle \\
\hline
\end{tabular}

TABLE 2: One-sample $t$-test results from the deviation magnitude comparison of identical twins and same individual values.

\begin{tabular}{|c|c|c|c|c|c|c|c|c|}
\hline \multirow[t]{2}{*}{ 3D measurements } & \multirow[t]{2}{*}{$N$} & \multirow[t]{2}{*}{$\begin{array}{l}\text { Mean } \\
\text { (dev.) }\end{array}$} & \multirow[t]{2}{*}{$( \pm) \mathrm{SD}$} & \multirow[t]{2}{*}{$t$} & \multirow[t]{2}{*}{$\mathrm{df}$} & \multirow[t]{2}{*}{$\begin{array}{c}\text { Sig. } \\
(2 \text {-tailed })^{*}\end{array}$} & \multicolumn{2}{|c|}{$\begin{array}{c}95 \% \\
\text { confidence } \\
\text { interval of the } \\
\text { difference }\end{array}$} \\
\hline & & & & & & & Lower & Upper \\
\hline R1MR & 24 & .035 & .338 & -2.324 & 23 & .029 & -.303 & -.018 \\
\hline R2MR & 24 & -.059 & .240 & -1.876 & 23 & .073 & -.193 & .009 \\
\hline R3MR & 24 & -.067 & .249 & 4.113 & 23 & .000 & .104 & .314 \\
\hline R2ML & 24 & .050 & .265 & 2.891 & 23 & .008 & .045 & .268 \\
\hline R3ML & 24 & -.009 & .375 & 6.429 & 23 & .000 & .334 & .650 \\
\hline R1LR & 24 & -.058 & .419 & -.363 & 23 & .720 & -.208 & .146 \\
\hline R2LR & 24 & -.097 & .484 & -1.427 & 23 & .167 & -.345 & .063 \\
\hline R3LR & 24 & .005 & .358 & -6.535 & 23 & .000 & -.628 & -.326 \\
\hline R1LL & 24 & -.023 & .343 & 6.649 & 23 & .000 & .321 & .610 \\
\hline R2LL & 24 & .032 & .437 & -9.740 & 23 & .000 & -1.054 & -.684 \\
\hline R3LL & 24 & -.028 & .458 & -6.798 & 23 & .000 & -.830 & -.442 \\
\hline
\end{tabular}

${ }^{*}$ Statistically significant differences at $p \leq 0.05$.

orthodontic treatment and with the values for different individuals $[10,11]$.

2.4. Statistical Analysis. A data set with the eleven variables was created for this study and compared with previously published values. Descriptive and comparative statistics were performed using SPSS 22.0 (Chicago, IL). One-sample $t$ tests were used to evaluate mean discrepancies for the eleven variables in both groups. A $p$ value of less than 0.05 was used as a criterion for statistical significance.

\section{Results}

3.1. Association of Different Rugae Lengths and Shapes between the Identical Twins. The palatal rugae length and shape were documented for both twins. Both twins were missing the first palatal rugae on the left side; one of the twins was missing the first palatal rugae on the right side as well. Table 1 summarizes the descriptive results.

3.2. Comparison between Identical Twins and Same Individual Values. A one-sample $t$-test was performed to compare the mean magnitude of deviation for each of the eleven variables between the pair of identical twins iTero scans and the previously published mean magnitude of deviation for the 24 same individual's scans taken at two time periods, 20 to 24 months apart $[10,11]$. Table 2 summarizes the descriptive statistics and the test results.

The results indicated that the following variables showed statistically significant mean differences: R1MR, R3MR, R2ML, R3ML, R3LR, R1LL, R2LL, and R3LL, with the $p$ values ranging from 0.029 to $<0.001$.

The Kolmogorov-Smirnov and Shapiro-Wilk tests showed that all variables have normal distribution for the different data sets.

3.3. Comparison between Identical Twins and Different Individual Values. A one-sample $t$-test was performed to compare the mean magnitude of deviation for each of the eleven variables between the pair of identical twins iTero scans and the previously published mean magnitude of deviation for the 28 different individual's scans $[10,11]$. Table 3 summarizes the descriptive statistics and the test results.

The results indicated that the following variables showed statistically significant mean differences: R1LL, R2LL, and R3LL, with the $p$ values ranging from 0.036 to $<0.001$. 
TABLE 3: One-sample $t$-test results from the deviation magnitude comparison of identical twins and different individual values.

\begin{tabular}{|c|c|c|c|c|c|c|c|c|}
\hline \multirow[t]{2}{*}{ 3D measurements } & \multirow[t]{2}{*}{$N$} & \multirow[t]{2}{*}{$\begin{array}{l}\text { Mean } \\
\text { (dev.) }\end{array}$} & \multirow[t]{2}{*}{$( \pm) \mathrm{SD}$} & \multirow[t]{2}{*}{$t$} & \multirow[t]{2}{*}{ df } & \multirow[t]{2}{*}{$\begin{array}{c}\text { Sig. } \\
(2 \text {-tailed })^{*}\end{array}$} & \multicolumn{2}{|c|}{$\begin{array}{c}95 \% \\
\text { confidence } \\
\text { interval of the } \\
\text { difference }\end{array}$} \\
\hline & & & & & & & Lower & Upper \\
\hline R1MR & 28 & .151 & .566 & -.417 & 27 & .680 & -.264 & .175 \\
\hline R2MR & 28 & -.095 & .762 & -.888 & 27 & .382 & -.424 & .168 \\
\hline R3MR & 28 & -.248 & .918 & .162 & 27 & .872 & -.328 & .384 \\
\hline R2ML & 28 & -.108 & 1.037 & -.012 & 27 & .991 & -.404 & .400 \\
\hline R3ML & 28 & -.211 & 1.172 & 1.308 & 27 & .202 & -.165 & .744 \\
\hline R1LR & 28 & -.047 & 1.057 & -.102 & 27 & .920 & -.430 & .390 \\
\hline R2LR & 28 & .140 & 1.318 & .385 & 27 & .703 & -.415 & .607 \\
\hline R3LR & 28 & .163 & 1.540 & -1.099 & 27 & .282 & -.917 & .277 \\
\hline R1LL & 28 & -.069 & 1.006 & 2.202 & 27 & .036 & .028 & .809 \\
\hline R2LL & 28 & -.015 & 1.325 & -3.657 & 27 & .001 & -1.430 & -.402 \\
\hline R3LL & 28 & -.195 & 1.534 & -2.772 & 27 & .010 & -1.398 & -.209 \\
\hline
\end{tabular}

${ }^{*}$ Statistically significant differences at $p \leq 0.05$.

\section{Discussion}

Palatal rugae are considered a focus of interest and reference landmarks in dentistry, orthodontics, and forensics due to their uniqueness, stability over time, and postmortem preservation $[10,11,25,26]$. The rugae patterns have been studied between different ethnicities, different individuals, and edentulous cases and following orthodontic treatment with expansion or extractions utilizing intraoral inspection, impressions, plaster casts, digital models, digital photography, and stereophotogrammetry $[4,5,9]$. It has also been documented that $93 \%$ of burn victims and $77 \%$ of human cadavers had no surface changes when remains were kept for a minimum period of 7 days [26]. The present case report aimed to evaluate the rugae pattern in identical twins, to determine the prevalence of similar features, and to compare the matching process with values previously published in the literature utilizing digital dental models obtained directly with the iTero intraoral scanner.

When comparing the identical twin values with the previously published data for other individual's longitudinal values, statistically significant differences were seen for eight out of the eleven variables: R1MR, R3MR, R2ML, R3ML, R3LR, R1LL, R2LL, and R3LL. When comparing the identical twin values with the previously published data for different individual values, statistically significant differences were seen for only three out of the eleven variables: R1LL, R2LL, and R3LL. The same three variables showed significant differences in both test groups. These results indicate that the monozygotic twin rugae patterns are not identical with each other and their differences are greater than individual changes seen in the reference group over time $[10,11]$.

A considerable correlation has been shown in fingerprint minutiae features, ridge count, ridge depth, and ridge separation in identical twins. Fingerprints of identical twins have significant generic similarity with some variations based on the micro details which are used for identification purposes [21]. Furthermore, tooth size has been suggested to have a strong hereditary component, with a trend for greater concordance in dental dimensions between monozygotic twins in comparison to dizygotic twins [27]. Experimental results have also indicated that although there is extra similarity and correlation between genetically identical vein patterns, they are distinguishable [28]. Palm prints have also demonstrated genetically related principal lines as well as some portion of weak lines for classifying identical twins [22]. Those findings are comparable with the results in this study. Correlations between the rugae lengths and shapes were observed between the identical twin pair. Both twins demonstrated the same shapes for all rugae except for the second rugae on the left side. Two of the rugae in both twins exhibited a definite continuous ring on the same location. Rugae lengths showed near-identical measurements for both twins.

This case report has assessed the palatal rugae among a pair of identical twins and has established baseline data for a larger-scale study that could be used for future comparative purposes in identical and/or fraternal twins and siblings. A longitudinal data analysis of rugae changes through time in a larger sample of multiple subjects of identical and/or fraternal twins could provide interesting results and improve the statistical power. An automated process and specialized computerized algorithm could also standardize the matching process, decrease human interaction in measurements, and increase the speed and accuracy of the quantitative analysis in large samples.

\section{Conclusion}

Digital models are taken on a daily basis in dentistry and orthodontics for records, restorative treatment, clear aligner treatment, retainer fabrication, and indirect bonding. Dental models are integrated in the personal electronic health record 
and can be requested by forensic institutes and law enforcement. This case report has shown that palatal rugae pattern has related but not identical features in a pair of monozygotic twins and a rugae evaluation could be a further reliable guide to forensic identification in identical twin cases.

\section{Consent}

The authors obtained consent forms from the patients.

\section{Conflicts of Interest}

The authors declare that there are no conflicts of interest regarding the publication of this paper.

\section{Acknowledgments}

This material is based on research sponsored by Align Technology, Inc., under the 2015 Align Scanner Award Program.

\section{References}

[1] H. Allen, “The palatal rugae in man," Dental Cosmos, vol. 31, pp. 66-80, 1889.

[2] W. R. English, S. F. Robison, J. B. Summitt, L. J. Oesterle, R. B. Brannon, and W. M. Morlang, "Individuality of human palatal rugae," Journal of Forensic Sciences, vol. 33, pp. 718-726, 1988.

[3] M. A. Almeida, C. Phillips, K. Kula, and C. Tulloch, "Stability of the palatal rugae as landmarks for analysis of dental casts," The Angle Orthodontist, vol. 65, pp. 43-48, 1995.

[4] L. T. Bailey, A. Esmailnejad, and M. A. Almeida, "Stability of the palatal rugae as landmarks for analysis of dental casts in extraction and nonextraction cases," The Angle Orthodontist, vol. 66, pp. 73-78, 1996.

[5] A. A. Barbieri, R. A. Scoralick, S. C. M. Naressi, M. E. L. Moraes, E. Daruge Jr., and E. Daruge, "The evidence of the rugoscopy effectiveness as a human identification method in patients submitted to rapid palatal expansion," Journal of Forensic Sciences, vol. 58, supplement 1, pp. S235-S238, 2013.

[6] S. C. Bansode and M. M. Kulkarni, "Importance of palatal rugae in individual identification," Journal of Forensic Sciences, vol. 1, pp. 77-81, 2009.

[7] L. Castro, G. Borges, I. Castro, O. Porto, and C. Estrela, "Change of incisive papilla height due to orthodontic movement: an evaluation in study models and three-dimensional images," Stomatos, vol. 18, pp. 52-59, 2012.

[8] I. M. Caldas, T. Magalhães, and A. Afonso, "Establishing identity using cheiloscopy and palatoscopy," Forensic Science International, vol. 165, no. 1, pp. 1-9, 2007.

[9] D. De Angelis, F. Riboli, D. Gibelli, A. Cappella, and C. Cattaneo, "Palatal rugae as an individualising marker: reliability for forensic odontology and personal identification," Science \& Justice, vol. 52, no. 3, pp. 181-184, 2012.

[10] E. Taneva, 3D Evaluation of Palatal Rugae for Human Identification, University of Illinois, Chicago, Ill, USA, 2014, University of Illinois,.

[11] E. Taneva, A. Johnson, G. Viana, and C. Evans, "3D evaluation of palatal rugae for human identification using digital study models," Journal of Forensic Dental Sciences, vol. 7, no. 3, pp. 244-252, 2015.
[12] E. Taneva, B. Kusnoto, and Evans C., "3D scanning, imaging and printing in orthodontics," in Orthodontics, S. Naretto, Ed., Intech Publishing, 2015.

[13] R. Ritter, "Uber die form, den verlauf und die typeneinteilung der gaumenleisten," Zeitschrift für Morphologie und Anthropologie, vol. 40, pp. 367-372, 1943.

[14] A. Indira, M. Gupta, and M. David, "Usefullness of palatal rugae patterns in establishing identity: preliminary results from Bengaluru city, India," Journal of Forensic Dental Sciences, vol. 4, no. 1, pp. 2-5, 2012.

[15] P. S. Fleming, V. Marinho, and A. Johal, "Orthodontic measurements on digital study models compared with plaster models: a systematic review," Orthodontics and Craniofacial Research, vol. 14, no. 1, pp. 1-16, 2011.

[16] T. V. Flügge, S. Schlager, K. Nelson, S. Nahles, and M. C. Metzger, "Precision of intraoral digital dental impressions with iTero and extraoral digitization with the iTero and a model scanner," American Journal of Orthodontics and Dentofacial Orthopedics, vol. 144, no. 3, pp. 471-478, 2013.

[17] A. K. Garg, "Cadent iTero's digital system for dental impressions: the end of trays and putty?" Dental Implantology Update, vol. 19, pp. 1-4, 2008.

[18] iTero: Intra Oral Digital Scanner, 2015 http://itero.com.

[19] J. J. Nora and F. C. Fraser, Medical Genetics: Principles and Practice, Lea \& Febiger, Philadelphia, Pa, USA, 4th edition, 1994.

[20] B. E. Hamilton, M. A. Joyce, M. J. K. Osterman, S. C. Curtin, and T. J. Matthews, "Births: final data for 2013," National Vital Statistics Reports, vol. 64, pp. 1-68, 2015.

[21] C. Derom, R. Derom, R. Vlietinck, H. V. Berghe, and M. I. Thiery, "Increased monozygotic twinning rate after ovulation induction,” The Lancet, vol. 329, no. 8544, pp. 1236-1238, 1987.

[22] A. K. Jain, S. Prabhakar, and S. Pankanti, "On the similarity of identical twin fingerprints," Pattern Recognition, vol. 35, no. 11, pp. 2653-2663, 2002.

[23] A. W.-K. Kong, D. Zhang, and G. Lu, "A study of identical twins' palmprints for personal verification," Pattern Recognition, vol. 39, no. 11, pp. 2149-2156, 2006.

[24] L. Lysell, "Plicae palatinae transversae and papilla incisiva in man; a morphologic and genetic study," Acta Odontologica Scandinavica, pp. 135-137, 1955.

[25] Thomas C. J and Kotze T. J., "The palatal ruga pattern: a new classification," The Journal of the Dental Association of South Africa, vol. 38, pp. 153-157, 1983.

[26] M. Muthusubramanian, K. S. Limson, and R. Julian, "Analysis of rugae in burn victims and cadavers to simulate rugae identification in cases of incineration and decomposition," Journal of Forensic Odonto-Stomatology, vol. 23, pp. 26-29, 2005.

[27] M. Kabban, J. Fearne, V. Jovanovski, and L. Zou, "Tooth size and morphology in twins," International Journal of Paediatric Dentistry, vol. 11, no. 5, pp. 333-339, 2001.

[28] H. Zhang, C. Tang, X. Li, and A. W. K. Kong, "A study of similarity between genetically identical body vein patterns," in Proceedings of the 2014 IEEE Symposium on Computational Intelligence in Biometrics and Identity Management (CIBIM '14), pp. 151-159, IEEE, Orlando, Fla, USA, December 2014. 


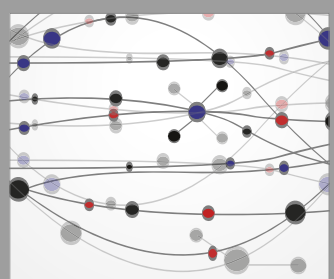

The Scientific World Journal
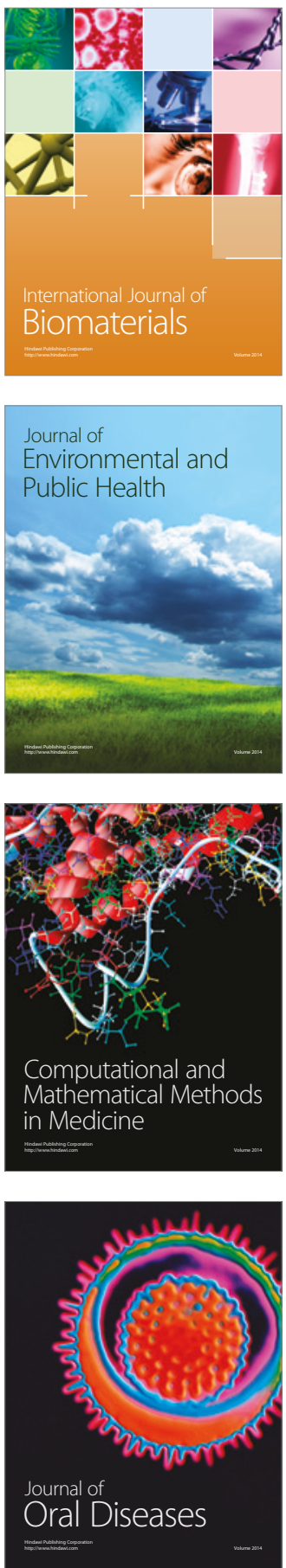
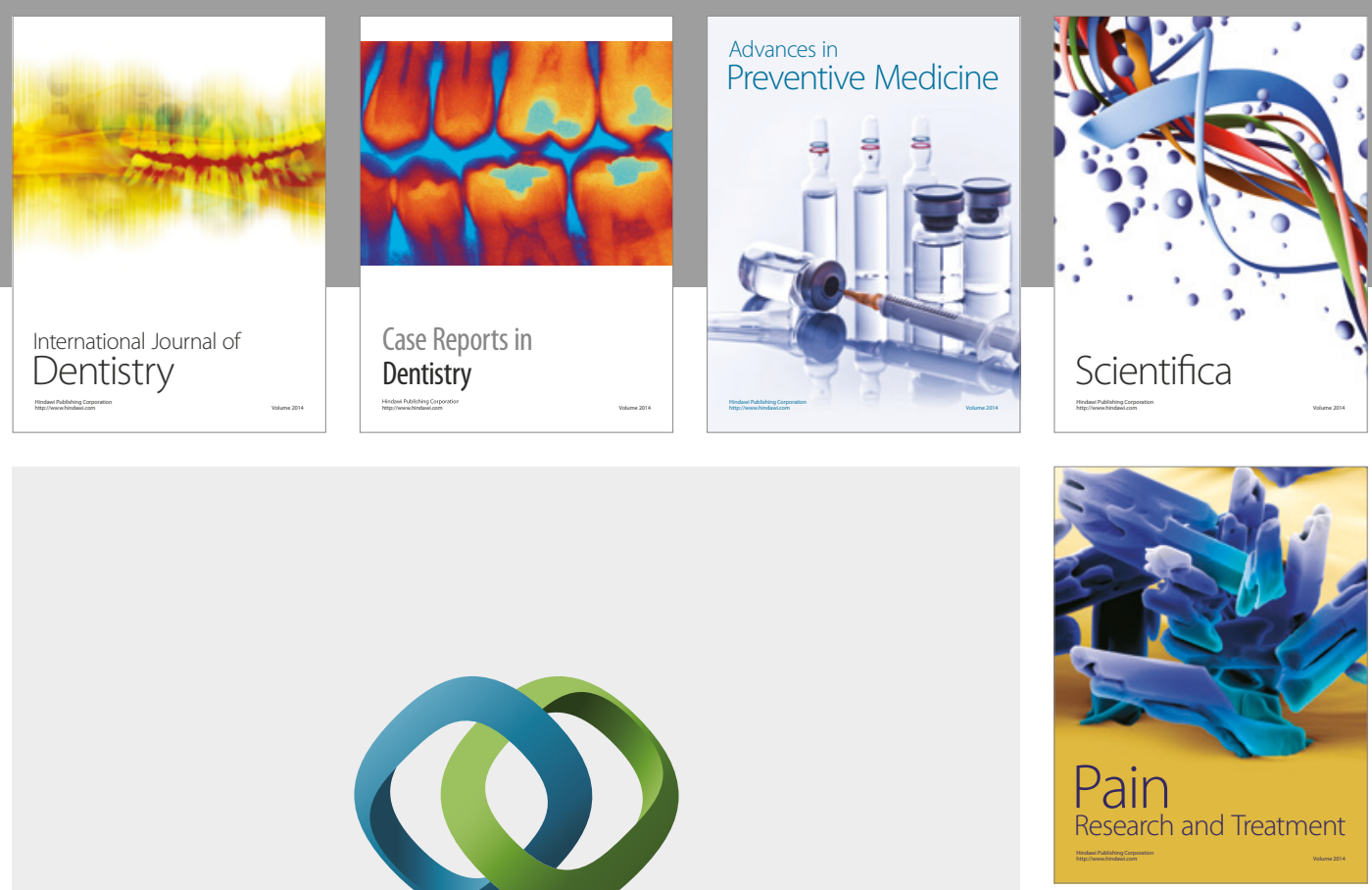

\section{Hindawi}

Submit your manuscripts at

https://www.hindawi.com
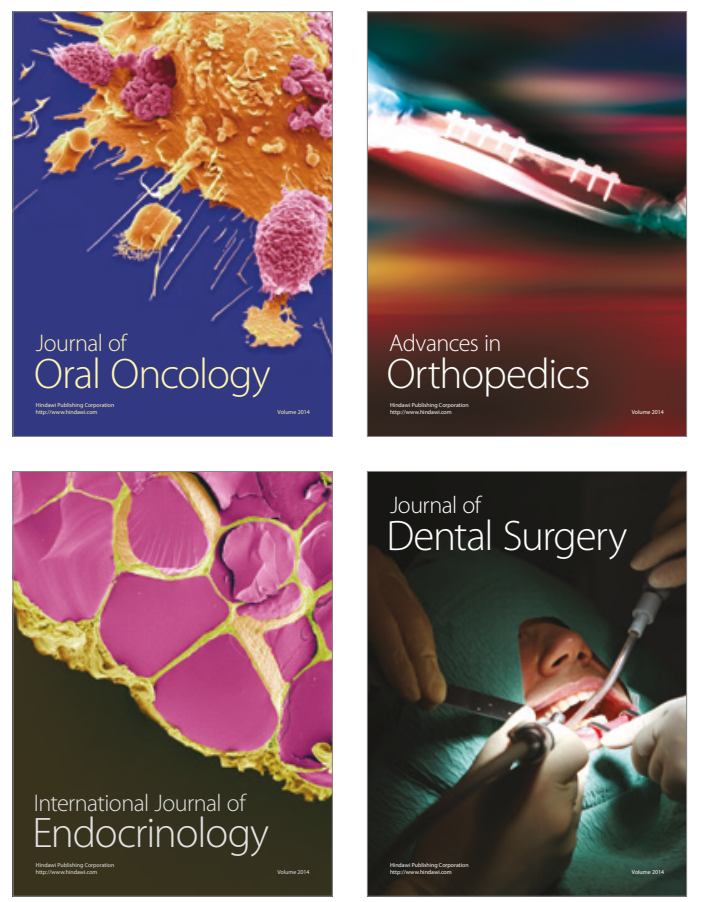
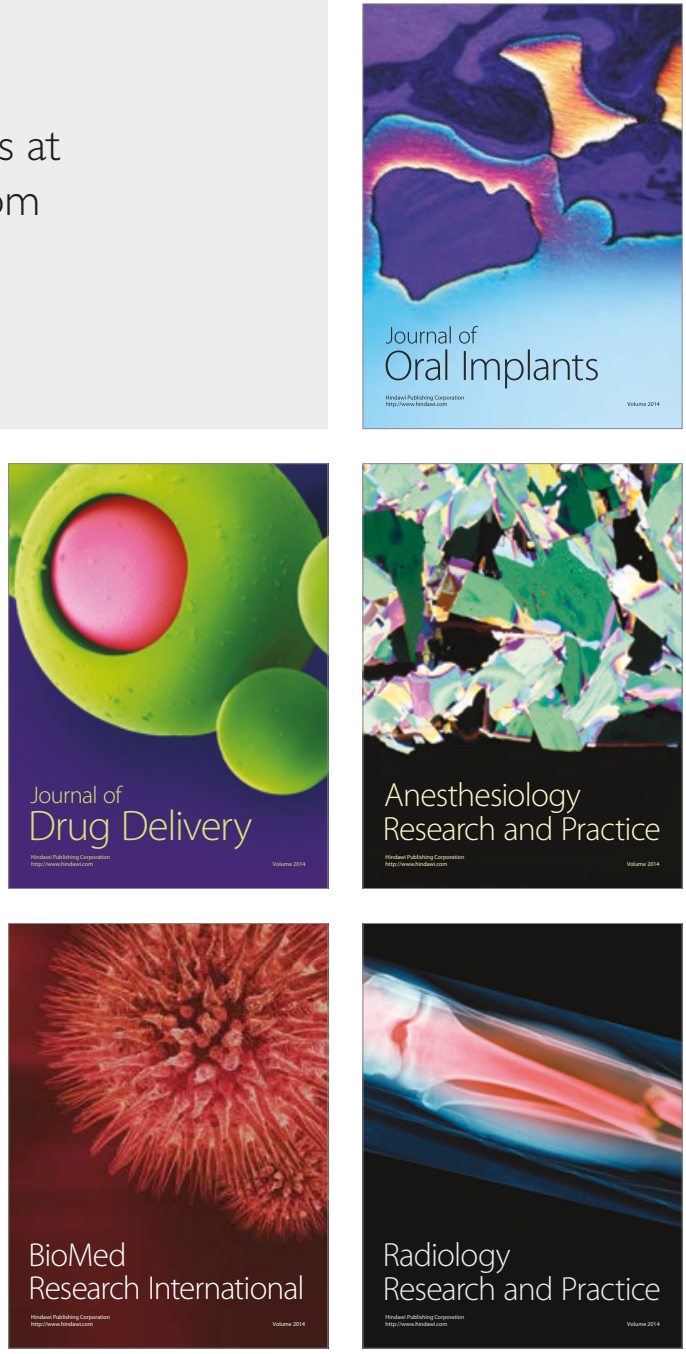